\title{
False-negative serology in patients with neuroborreliosis and the value of employing of different borrelial strains in serological assays
}

\author{
REINHARD KAISER \\ Neurologische Klinik und Poliklinik der Albert-Ludwigs-Universität Freiburg, Breisacher Straße 64, \\ D-79106 Freiburg, Germany
}

\begin{abstract}
The risk of obtaining false-negative results in serological assays in serum and CSF specimens with only one strain of Borrelia burgdorferi sensu lato as antigen was investigated in 79 patients with neuroborreliosis with specimens obtained at initial presentation. Serum antibodies were assessed by immunoblotting; the criteria of Hauser et al. were used to evaluate the test. The intrathecal synthesis of borrelial-specific IgM and IgG antibodies was examined by enzyme immunoassay (EIA). Strains of $B$. burgdorferi sensu stricto (BbZ160), B. garinii (Bbii50) and B. afzelii (PKO) served as sources of antigen in both assays. All patients produced either a positive IgM or IgG test in serum with at least one strain of $B$. burgdorferi sensu lato. Reactivity of IgM or IgG antibodies, or both, with antigens of all three strains was demonstrated in $67(85 \%)$ of 79 sera. The correlation of results of immunoblotting with different strains was significantly better for IgG $(85 \%)$ than for IgM antibodies (54\%). The variability of positive IgM reactions in 18 specimens was mainly due to the fact that the antibodies were directed to the relevant variable outer-surface protein $\mathrm{C}$ (p23). Intrathecal synthesis of IgG antibodies was demonstrated in 58 patients $(81 \%)$ of 72 and of IgM antibodies in 25 of 58 patients. No patient had isolated intrathecal synthesis of IgM antibodies. The majority of CSF samples (56 of 58) were assessed as IgG antibodypositive, independent of the borrelial strain used as antigen in EIA, whereas only 10 of 25 IgM antibody-positive CSF specimens reacted with all three strains. All patients in the study had intrathecal antibody synthesis demonstrable at 6-week follow-up. From this study it is concluded that there is a small, but real, risk of false-negative serological findings at the time of initial clinical presentation in patients with typical symptoms of neuroborreliosis. In these patients a negative serological result with one strain should prompt the repetition of the test with other strains of $B$. burgdorferi sensu lato.
\end{abstract}

\section{Introduction}

The diagnosis of neuroborreliosis is a clinical decision which should be supported by laboratory data. The first laboratory step is to test for serum antibodies in a screening assay. A positive finding should be confirmed by a more specific assay, such as immunoblotting or EIA with recombinant borrelial proteins [1]. A positive finding in a confirmation assay should prompt investigation of the cerebrospinal fluid (CSF), which typically shows lymphocytic pleocytosis, impairment of the blood-CSF barrier and intrathecal synthesis of immunoglobulins [2]. The latter findings are suppor-

Received 21 July 1999; revised version accepted 14 March 2000.

Corresponding author: Dr R. Kaiser. tive, but not proof, of neuroborreliosis. The suspected diagnosis is confirmed either by the demonstration of intrathecal synthesis of Borrelia burgdorferi sensu latospecific IgG or IgM antibodies or by the demonstration of borrelial DNA in the CSF by PCR [3]. In Europe, three species of $B$. burgdorferi sensu lato are pathogenic for man. Many antigens of B. burgdorferi sensu lato have been shown to vary between the three species B. burgdorferi sensu stricto, B. garinii and $B$. afzelii [4]. This may influence the serodiagnosis of the disease, possibly resulting in false-negative findings, if specimens are tested for antibodies against antigens from one species only.

The aim of the present study was to evaluate the sensitivity of detection of specific antibodies in serum and CSF when different borrelial species are employed 
as antigen. The serum antibody response was investigated by immunoblotting and the criteria of Hauser and co-workers were used for the evaluation of antibody bands [5]. Intrathecal synthesis of B. burgdorferi sensu lato-specific antibodies was investigated by sonicate ELISA [6, 7].

\section{Patients and methods}

\section{Subjects}

CSF and serum samples were obtained from 79 patients with neuroborreliosis who had been admitted to the Department of Neurology of the University of Freiburg between 1991 and 1999. Sixty-five patients had acute neuroborreliosis (duration of symptoms $\leqslant 6$ months; meningoradiculitis, 56; encephalitis, 7; myelitis, 2) and 14 had chronic neuroborreliosis (duration of symptoms $>6$ months; encephalomyelitis). The diagnosis of neuroborreliosis was based on clinical symptoms, lymphocytic pleocytosis in the CSF and assessment of B. burgdorferi-specific IgM or IgG antibodies in serum by routine serological tests as follows: a titre $>320$ in a passive haemagglutination assay with a mixture of antigens from $B$. burgdorferi sensu stricto (strain Z37) and B. afzelii (strain Bo23) or a positive titre $(\operatorname{IgM}>24, \operatorname{IgG}>32)$ in an IFA employing $B$. burgdorferi sensu stricto as antigen or both. Specimens were tested at the Department of Immunology in the Institute of Medical Microbiology of the University of Freiburg. Intrathecal synthesis of B. burgdorferi sensu lato-specific $\operatorname{IgG}$ or $\operatorname{IgM}$ antibodies, or both, in sonicate EIA was demonstrated on admission to hospital in $67(85 \%)$ patients and at follow-up examinations after 6 weeks in all patients. The CSF findings of the patients have been presented in detail previously [8].

\section{SDS-PAGE and immunoblotting}

SDS-PAGE and immunoblotting were performed as described previously [9]. Proteins from different strains of $B$. burgdorferi sensu lato (B. burgdorferi sensu stricto, BBZ160; B. garinii, Bbii50; B. afzelii, PKO) were separated individually in a discontinuous SDSmini-gel. Each test included a positive and a negative serum sample. Blots were evaluated according to the criteria of Hauser et al. [5]. Monoclonal antibodies (MAbs) were used to identify individual borrelial proteins. The following MAbs were kindly provided by M. Kramer (Department of Immunology, University of Heidelberg, Germany): LA95 against p15, LA7 against p20, LA 25 against p34, LA22 against p41 and LA114.1 against p83. A further two MAbs were provided by B. Wilske (Max von Pettenkofer Institute of Medical Microbiology, University of Munich, Germany): L30 against p30 and LA60 against p60.

\section{Enzyme immunoassay}

Intrathecal synthesis of $B$. burgdorferi sensu latospecific antibodies in the CSF was determined by an enzyme-linked immunosorbent assay (EIA) as described previously [10]. Microtitration plates were coated individually with $100 \mu \mathrm{l}$ of $B$. burgdorferi sensu stricto (BBZ160; $20 \mu \mathrm{g} / \mathrm{ml})$, B. garinii (Bbii50) or $B$. afzelii (PKO) sonicate in phosphate-buffered saline (PBS). Specific antibody synthesis in the CNS was assessed from the antibody index (AI), which is defined as the ratio between the $\mathrm{CSF} /$ serum quotient for specific antibodies and the quotient of total $\operatorname{IgG}$ or IgM concentrations in CSF and serum. AI values $>1.5$ were considered indicative of an intrathecal antibody response to B. burgdorferi sensu lato antigens [7]. Calculations of the intrathecal synthesis of specific IgM antibodies were performed in a similar fashion.

\section{Statistical analysis}

The frequency of positive results in both groups was analysed by the $\chi^{2}$ test, the correlation between findings in EIA by regression analysis (r) with SPSS/ $\mathrm{PC}^{+}$software. A $\mathrm{p}$ value $<0.05$ was considered significant.

\section{Results}

\section{B. burgdorferi sensu lato-specific antibodies in serum}

IgG antibodies were detected more frequently than IgM antibodies. In total, only eight patients with acute neuroborreliosis were $\operatorname{IgM}$ positive but negative for IgG antibodies. Two of these latter patients suffered from facial nerve palsy, three from radiculitis and three from acute meningoencephalitis. The presumptive incubation time was between 3 and 5 weeks.

The frequencies of serum $\operatorname{IgM}$ and $\operatorname{IgG}$ antibodies reacting with proteins of individual strains of $B$. burgdorferi sensu lato are shown in Table 1. All patients displayed either $\operatorname{IgM}$ or $\operatorname{IgG}$ antibodies reacting with proteins of at least one strain of $B$. burgdorferi sensu lato. $\operatorname{IgM}$ or $\operatorname{IgG}$ antibodies that

Table 1. Prevalence of serum IgM and IgG antibodies to $B$. burgdorferi sensu lato in immunoblotting

\begin{tabular}{lcc}
\hline & $\begin{array}{c}\text { Number/number tested (\%) of } \\
\text { sera with antibodies }\end{array}$ \\
\cline { 2 - 3 } Positive reactions with & IgM & $\operatorname{IgG}$ \\
\hline at least one species & $39 / 79(49)$ & $71 / 79(90)$ \\
only one species & $14 / 39(36)$ & $5 / 71(7)$ \\
two species & $4 / 39(10)$ & $6 / 71(8)$ \\
three species & $21 / 39(54)$ & $60 / 71(85)$ \\
B. burgdorferi sensu stricto & $25 / 79(32)$ & $70 / 79(89)$ \\
B. garinii & $29 / 79(38)$ & $71 / 79(90)$ \\
B. afzelii & $32 / 79(40)$ & $65 / 79(82)$ \\
\hline
\end{tabular}


recognised all three strains were present in 67 of $(85 \%)$ 79 sera. However, 12 specimens gave positive reactions only with one or two strains of $B$. burgdorferi sensu lato. Three sera revealed only IgM antibodies that then reacted with a single strain (B. afzelii, two; B. garinii, one).

The variability of positive findings after testing for IgM antibodies in 18 samples was most often associated with a specificity of these antibodies for the outersurface protein (Osp) $\mathrm{C}$; in five further patients the specificity of the antibodies was for the flagellin protein (p41) and in one patient for BmpA (p39). Of
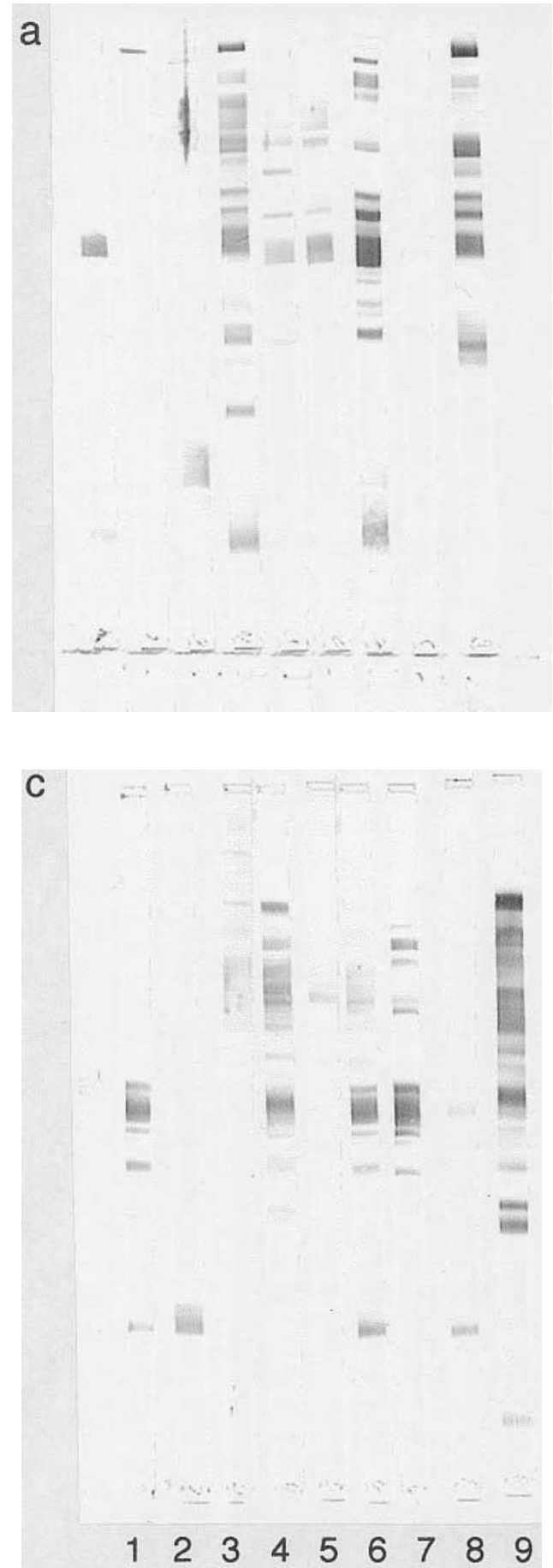

18 IgM-positive sera which did not react with all three strains of $B$. burgdorferi sensu lato, 11 were positive for B. afzelii, 7 for B. garinii and 4 for B. burgdorferi sensu stricto. Four of 11 sera that reacted with $B$. afzelii were also positive when tested with $B$. burgdorferi sensu stricto, but negative when tested with $B$. garinii. Seven sera reacted with OspC of $B$. garinii but not with OspCs of the other strains. Failure to detect $\operatorname{IgG}$ antibodies against proteins from all three strains $(n=11)$ was due to the specificity of these antibodies for OspC in five patients and for p17, p30, p43 and p58 in a further six patients. The variability of individual antibody responses is shown in Fig. 1.

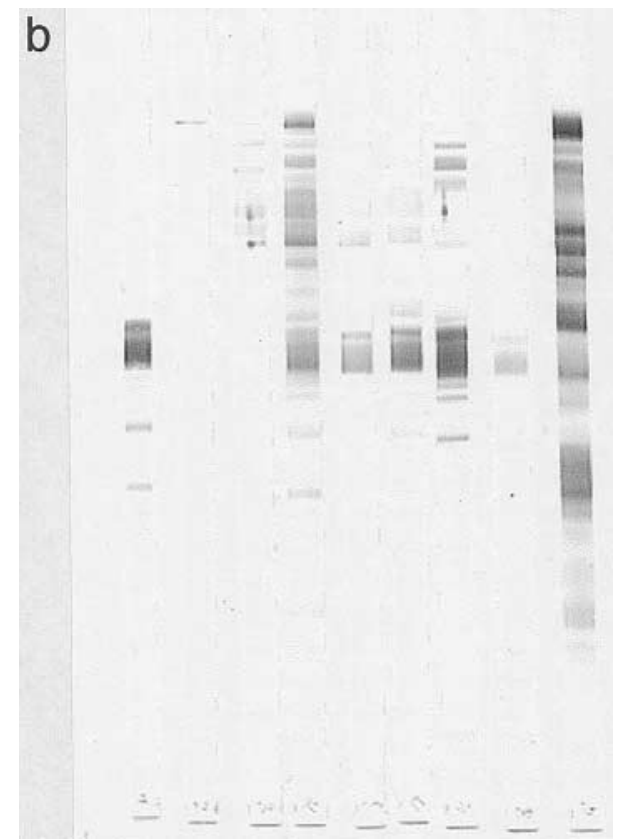

Fig. 1. Variable antibody response to proteins of different strains of B. burgdorferi sensu lato: (a) B. afzelii, (b) $B$. burgdorferi sensu stricto, (c) B. garinii. Lanes 1 and 2 (IgM), 3-7 (IgG); serum samples from patients with neuroborreliosis. 


\section{Intrathecal synthesis of B. burgdorferi sensu lato- specific antibodies}

Due to the limited amounts of CSF available, the intrathecal synthesis of agent-specific antibodies was investigated in only 72 specimens. Of these, 25 (35\%) were positive for $\operatorname{IgM}$ and $58(81 \%)$ were positive for IgG antibodies. All patients with an elevation of the IgM antibody index also showed an intrathecal synthesis of $B$. burgdorferi sensu lato-specific IgG antibodies. However, while the majority of $\operatorname{IgM}$ antibody-positive specimens did not react with proteins of all three strains (Table 2), the majority of $\mathrm{IgG}$ antibody-positive specimens did. No preference for any particular strain as a suitable antigen in EIA was seen: intrathecally-produced $\operatorname{IgM}$ and $\operatorname{IgG}$ antibodies reacted with proteins of the three strains with similar frequencies. The correlation between EIA results from tests with different strains was significantly better for IgG than for IgM antibodies (Table 3).

\section{Discussion}

The purpose of the present study was to investigate the risk of obtaining false-negative serological findings in patients with proven neuroborreliosis. The diagnosis was established on the basis of clinical findings fulfilling the criteria recommended recently by the European Union Concert Action on Risk Assessment in Lyme borreliosis and by the demonstration of intrathecal synthesis of B. burgdorferi sensu lato-specific IgG or IgM antibodies 6 weeks at the latest after admission to hospital [11]. The criteria of Hauser et al. were used for the evaluation of the immunoblot, because in a previous study these criteria were shown to be more sensitive than those of Engström (and the CDC) [9].

Table 2. Intrathecal synthesis of $\operatorname{IgM}$ and $\operatorname{IgG}$ antibodies to B. burgdorferi sensu lato

\begin{tabular}{lrc}
\hline & \multicolumn{2}{c}{$\begin{array}{c}\text { Number/number tested (\%) of } \\
\text { sera with antibodies }\end{array}$} \\
\cline { 2 - 3 } Positive reactions with & \multicolumn{1}{c}{$\operatorname{IgM}$} & IgG \\
\hline at least one species & $25 / 72(35)$ & $58 / 72(81)$ \\
only one species & $8 / 25(32)$ & $1 / 58(2)$ \\
two species & $7 / 25(28)$ & $1 / 58(2)$ \\
three species & $10 / 25(40)$ & $56 / 58(96)$ \\
B. burgdorferi sensu stricto & $17 / 72(24)$ & $57 / 58(98)$ \\
B. garinii & $18 / 72(25)$ & $57 / 58(98)$ \\
B. afzelii & $17 / 72(24)$ & $57 / 58(98)$ \\
\hline
\end{tabular}

Table 3. Correlation coefficients (r) for intrathecally produced $\operatorname{IgM}$ and $\operatorname{IgG}$ antibodies against different strains of B. burgdorferi sensu lato

\begin{tabular}{lcc}
\hline Correlation of positive results (AI $\uparrow$ ) & $\operatorname{IgM}$ & $\operatorname{IgG}$ \\
\hline B. afzelii $\Leftrightarrow$ B. burgdorferi sensu stricto & 0.735 & 0.922 \\
B. afzelii $\Leftrightarrow$ B. garinii & 0.447 & 0.936 \\
B. burgdorferi sensu stricto $\Leftrightarrow$ B. garinii & 0.635 & 0.950 \\
\hline
\end{tabular}

Considering the heterogeneity of many antigens of $B$. burgdorferi sensu stricto, B. garinii and $B$. afzelii, the risk of false-negative findings for $\mathrm{IgG}$ and $\mathrm{IgM}$ antibodies in immunoblotting was calculated to be $c$. $15 \%$. The risk became evident only when samples were tested against one borrelial strain. Theoretically, this risk could be alleviated by mixing proteins from individual borrelial strains. Because of the problems in recognition of individual proteins, this procedure is not recommended for immunoblotting, although it may be useful for antibody testing in a sonicate EIA. The dominance of $\mathrm{IgG}$ antibodies against $B$. garinii in immunoblotting reported by Hauser et al. was confirmed in this study [5]. The lower absolute frequency of serum $\operatorname{IgG}$ antibodies $(71 \%)$ in their study is probably due to collection of serum samples at an earlier stage of disease (median duration of symptoms was 3 weeks versus 2 months in the present study). Whereas Hauser et al. found $\operatorname{IgG}$ antibodies to $B$. burgdorferi sensu stricto and B. afzelii with similar frequencies (66 and 64\%, respectively), in the present study IgG antibodies to B. burgdorferi sensu stricto $(89 \%)$ were demonstrated more frequently than those to $B$. afzelii $(82 \%)$. The frequencies of IgM antibodies specific for individual borrelial species in the present study (Table 1) were similar to those in the study by Hauser et al. (B. garinii, 43\%; B. afzelii, 39\%; B. burgdorferi sensu stricto, 36\%). However, the findings from both studies do not lend support to the idea that $B$. garinii is the predominant borrelial strain causing neurological manifestations in borreliosis.

The risk of not detecting IgM antibodies in patients who were positive only when tested with the appropriate strains of $B$. burgdorferi sensu lato arises mainly from the specificity of these antibodies for OspC and $\mathrm{p} 41$. This observation is in agreement with the findings of other investigators [12-16], who have already pointed out the diagnostic relevance of strain differences concerning OspC.

On account of the limited amounts of CSF available in the present study, the specificity of intrathecally produced IgM and IgG antibodies for individual proteins of $B$. burgdorferi sensu lato could not be determined by immunoblotting. It can only be speculated that the variability of locally produced $\operatorname{IgM}$ antibodies was mainly due to their strain specificity for the outer-surface proteins $\mathrm{C}$ - as has been shown for serum antibodies. The heterogeneity of the intrathecal IgM response for individual borrelial strains is reflected by the lower correlation coefficient, compared with the IgG response (Table 3). As all patients with intrathecal synthesis of specific IgM antibodies showed an elevation of the $\mathrm{IgG}$ antibody index, the variability of the IgM response in the CSF is of only minor significance for the diagnosis of neuroborreliosis. However, in a previous study with a different study population, five of 67 patients showed an intrathecal synthesis of specific $\operatorname{IgM}$, but not of $\operatorname{IgG}$ antibodies 
[10]. Unfortunately, CSF samples from these patients were no longer available for investigation of the specificity of IgM antibodies for proteins of individual borrelial strains. The high correlation coefficient of positive results concerning the intrathecal synthesis of specific IgG antibodies corresponds to the observation that $96 \%$ of patients had an elevation of the $\mathrm{IgG}$ antibody index independent of the borrelial strain used as antigen in EIA. This correlation supports the assumption that, in neuroborreliosis, a considerable percentage of intrathecally synthesised $\mathrm{IgG}$ antibodies are cross-reactive and not highly specific for $B$. burgdorferi sensu lato [17].

In conclusion, in patients who suffer from typical symptoms of neuroborreliosis (facial palsy, radiculitis, meningitis, encephalitis, myelitis) and who present with inflammatory findings in the CSF, a negative result after testing with one strain of B. burgdorferi sensu lato should prompt the repetition of the test with other strains of B. burgdorferi sensu lato.

This work was supported by the Bundesministerium für Bildung und Forschung (01KI 9504/9). I thank P. Völker for her expert and skillful technical assistance and Professor Batsford for help in editing the manuscript.

\section{References}

1. CDC/DVBID. Standardisation of Lyme disease serodiagnosis: working group meet to chart progress. $C D C$ 1994; 5: 1-3.

2. Kaiser R. Variable CSF findings in early and late Lyme neuroborreliosis: a follow-up study in 47 patients. $J$ Neurol 1994; 242: 26-36.

3. Halperin JJ, Logigian EL, Finkel MF, Pearl RA. Practice parameters for the diagnosis of patients with nervous system Lyme borreliosis (Lyme disease). Neurology 1996; 46: 619-627.

4. Wilske B, Busch U, Fingerle $\mathrm{V}$ et al. Immunological and molecular variability of OspA and OspC. Implications for Borrelia vaccine development. Infection 1996; 24: 208-212.

5. Hauser U, Lehnert G, Lobentanzer R, Wilske B. Interpretation criteria for standardized Western blots for three European species of Borrelia burgdorferi sensu lato. J Clin Microbiol 1997; 35: 1433-1444.

6. Reiber H, Lange P. Quantification of virus-specific antibodies in cerebrospinal fluid and serum: sensitive and specific detection of antibody synthesis in brain. Clin Chem 1991; 37: $1153-1160$.

7. Kaiser R, Lücking $\mathrm{CH}$. Intrathecal synthesis of specific antibodies in neuroborreliosis. Comparison of different ELISA techniques and calculation methods. J Neurol Sci 1993; 118: 64-72.

8. Kaiser R, Rauer S. Advantage of recombinant borrelial proteins for serodiagnosis of neuroborreliosis. J Med Microbiol 1999; 48: 5-10.

9. Kaiser R, Rauer S. Serodiagnosis of neuroborreliosis: comparison of reliability of three confirmatory assays. Infection 1999; 27: 177-182.

10. Kaiser R, Rauer S. Analysis of the intrathecal immune response in neuroborreliosis to a sonicate antigen and three recombinant antigens of Borrelia burgdorferi sensu stricto. Eur J Clin Microbiol Infect Dis 1998; 17: 159-166.

11. Stanek G, O'Connell S, Cimmino M et al. European Union concerted action on risk assessment in Lyme borreliosis: clinical case definitions for Lyme borreliosis. Wien Klin Wochenschr 1996; 108: 741-747.

12. Wilske N, Fingerle V, Preac-Mursic V et al. Immunoblot using recombinant antigens derived from different genospecies of Borrelia burgdorferi sensu lato. Med Microbiol Immunol (Berl) 1994; 183: 43-59.

13. Theisen M, Frederiksen B, Lebech A-M, Vuust J, Hansen K. Polymorphism in ospC gene of Borrelia burgdorferi and immunoreactivity of OspC protein: implications for taxonomy and for use of OspC protein as a diagnostic antigen. J Clin Microbiol 1993; 31: 2570-2576.

14. Mathiesen MJ, Hansen K, Axelsen N, Halkier-Sorensen L, Theisen M. Analysis of the human antibody response to outer surface protein C (OspC) of Borrelia burgdorferi sensu stricto, B. garinii, and B. afzelii. Med Microbiol Immunol (Berl) 1996; 185: $121-129$.

15. Probert WS, Crawford M, Cadiz RB, LeFebvre RB. Immunization with outer surface protein (Osp) A, but not OspC, provides cross-protection of mice challenged with North American isolates of Borrelia burgdorferi. J Infect Dis 1997; 175: 400-405.

16. Rauer S, Spohn N, Rasiah C, Neubert U, Vogt A. Enzymelinked immunosorbent assay using recombinant $\mathrm{OspC}$ and the internal $14-\mathrm{kDa}$ flagellin fragment for serodiagnosis of early Lyme disease. J Clin Microbiol 1998; 36: 857-861.

17. Kaiser R. Intrathecal immune response in neuroborreliosis: importance of cross-reactive antibodies. Zentralbl Bakteriol 1995; 282: 303-314. 